\title{
Analyzing the cause of human electrical accidents using Swiss Cheese model
}

\author{
Beena Puthillath \\ Department of Electrical Engineering, School of Engineering, \\ Cochin University of Science and Technology, Kochi, India \\ Bhasi Marath \\ School of Management Studies, Cochin University of Science and Technology, \\ Kochi, India, and \\ Babu Chembakthuparambil Ayappan \\ Department of Electrical Engineering, School of Engineering, \\ Cochin University of Science and Technology, Kochi, India
}

\begin{abstract}
Purpose - This study aims to explore the factors influencing electrical accidents. Here, the authors aim to understand and model the causes of electrical accidents at multiple levels.

Design/methodology/approach - In the study, the authors have tried to put causes of accidents in the electricity distribution segment, in the framework of the Swiss Cheese model. Delphi kind of expert survey was conducted to find the Cheese Slice (level) and the causes (holes) for electrical accidents. Inputs from a hundred experts having more than five years of experience in electrical utility companies have been used to find Cheese Slice and holes, to explain the occurrence of an electrical accident.

Findings - Effective training for safe work practices, safe knowledge and closer supervision would go a long way to plug the holes in the Cheese Slice in human factors. The difference in perception of managers, supervisors and workers on the importance of various causes of electrical accidents are also presented and discussed.

Research limitations/implications - This research is based on expert opinion and survey where respondent perception is reported. Actual accident data has not been used here.

Practical implications - The holes or causes of accidents at different levels (Cheese Slice) have been identified for plugging or removal for better safety.

Social implications - Electrical energy is widely used, and therefore, electrical safety is a social concern and also improving it is a social need.

(C) Beena Puthillath, Bhasi Marath and Babu Chembakthuparambil Ayappan. Published in VilakshanXIMB Journal of Management. Published by Emerald Publishing Limited. This article is published under the Creative Commons Attribution (CC BY 4.0) licence. Anyone may reproduce, distribute, translate and create derivative works of this article (for both commercial and non-commercial purposes), subject to full attribution to the original publication and authors. The full terms of this licence maybe seen at http:// creativecommons.org/licences/by/4.0/legalcode

The authors would like to thank Safety Department of utility sector and responses received. This made research possible for valuable insights into this topic.

Declaration: The authors declare that there is no financial funding for the research activity and no known competing financial interests or personal relationship that could have appeared to influence the work reported in this paper.
\end{abstract}

Cause of human electrical accidents

Received 14 January 2021 Revised 4 April 2021 27 June 2021 30 July 2021

Accepted 11 August 2021 
Originality/value - The study contributes to electrical safety issues in the electrical utility sector.

Keywords Accidents, Electricity distribution, Perception differences, Swiss Cheese model

Paper type Research paper

\section{Introduction}

Accidents have been a major concern of the top management in hazardous industries. Though in earlier days the causes of accidents were always attributed to the accident zone or equipment involved, now accident are understood to be having deeper and wider causes even covering practices in society and industry. Studies on electrical accidents reported in the literature have mostly focused on causes in the proximity of the accident and have not taken a wider view of the phenomena leading to the accident.

In industrial situations, even the causes of the accident in the proximity of the site and time were not in the control of the people there but were the result of decisions taken at a different time by different persons at different places. This being the case there is a need to model accidents and bring out causes at the organization level, working environment and system level, workplace and human issues all in one model showing their interrelationship. This approach will lead to an integrated holistic approach for reducing accidents and improving safety specially related to electrical accidents.

\section{Review of literature}

\subsection{Accident modeling}

An accident is an undesirable event and it results in either injury to a person or damage to property. Accidents are a threat in any industry. According to various studies conducted in the past it is clearly proven that the growth and survival of any industry has a direct relation with safety. Safety in industry is a complex phenomenon. To improve safety, we have to know the factors that cause accidents or hazards (Mullai and Paulson, 2011; Sklet, 2016). Information about safety issues helps decision-makers in improving safety standards through developing effective management strategies (VinodKumar and Bhasi, 2007). Identifying, addressing and eliminating threats helps in reducing the risk of accident (Thomas and Bhasi, 2011). Continuous improvement with an efficient feedback mechanism helps in understanding and avoiding factors influencing accident (Mallik, 2014).

The causes of serious injuries can be depicted in an Injury Pyramid (Heinrich, 1950). There are two approaches to reducing accidents, first, as accidents are caused by chance events (hazards), the probability of occurrence these chance events have to be minimized. Second, the seriousness of the effect of the event chance (hazard) has to be minimized, say by the use of personal protective equipment (PPE). Knowing the root cause of an accident will help to reduce the rate of occurrence and formulate effective prevention strategies. Many theories such as Heinrich domino theory, Ferrell's human factor model, Petersen's accident incident model, System model and Swiss Cheese model (Burke et al., 2008; Khosravi et al., 2014) may be used to depict, understand the factors involved in accidents and reduce them.

Heinrich's (1950) in his theory explains accidents using dominos. The dominos fall over one another and create a chain of events. It has a single chain reaction of incidence. Heinrich explained various stages in accident causation (Census of Fatal Occupational Injuries, 2014; Marshall and Singer, 2018; A Guide to Measuring Health and Safety Performance, 2001). The first stage is the social environmental and ancestral one which encompasses things 
leading to undesirable traits of a person. Genetics or inherent behavior is the commonly used term. The second stage is a fault in person or personal characteristics (Low et al., 2019; Choudhry, 2014; Cooper, 2002; A Guide to Measuring Health and Safety Performance, 2001). Ignorance, temper, etc., are some of the personal traits. The third stage is due to unsafe conditions or unsafe acts which lead to specific incidents. This type of stage is identifiable and nearer to accident proximity. The next stage is the accident itself. The last one is injury or an unfortunate outcome of an accident. Organizations can have procedures to deal with accidents and reduce injury or loss (Casey et al., 2017; Dedobbeleer and Beland, 1991; Gludenmund, 2002).

Ferrell's model is about the human factor which explains multiple causes and also specifies about the causes (Chi et al., 2009; Cigularov, 2013; Huang et al., 2006). Ferrell defines an accident as an error of an individual and defines the general cause of the accident, namely, overloaded activity, incompatibility of activity and improper activity. Each general cause has several specific causes. Improper activity may be, lack of knowledge or deliberate risk taking. The next one called incompatibility is a little complex compared to improper activity. It encompasses improper response to the situation and environmental characteristics. The third class called overload is more complex and is related to the emotional state of a person (Dedobbeleer and Beland, 1991; Kapp, 2021; Newaz et al., 2019). It also includes unmotivated conditions, physical and educational background, situational factors like drugs, job-related factors such as work pressure and other environmental factors like noise or distraction.

Petersen's incident accident model is a modification of Ferrell's model. He has included the concepts of ergonomics and decision errors. It also includes unconscious desire, poor logical decision, system failure, poor policy, not detecting mistakes and lack of training (Fang et al., 2015; Hayes et al., 1998; Mullen et al., 2017; Tsang et al., 2017).

Based on the Domino theory adapted from Heinrich 1931, the major factors of accidents are social, environmental, fault of the person, unsafe act or physical hazard, accident and injury. The social environment can be due to undesirable characteristics such as greed and stubborn, influenced by the environment. It is thought of as nature or inherent behavior. The fault of a person includes temper, overconfidence, inconsideration, violent behavior, etc. It is described as nurtured or acquired behavior. The unsafe act can be not wearing PPE, improper earth, slippery, etc. Injury is the direct impact of an accident which can be burn, fracture or even death.

Reason's Swiss Cheese model is based on Heinrich's Domino theory. Barriers are depicted as slices of the Swiss Cheese while the hole in the Cheese represents latent failure (Figure 1).

Active failure is directly linked with accidents and failing to stop can cause adverse events. Active failure leads to immediate consequences while latent failure may take days or months before contributing to the accident. Active failure can be easily identified. Every layer is indicated by a Cheese Slice and problem or failure by holes of Cheese. The failure can be active or latent. Active failure contributes directly to the accident while latent failure may remain dormant for some period until they lead to a catastrophic accident. For any accident to happen the holes have to be in a line. If circumstances favor and holes align then accidents occur (Fang et al., 2015; Johnson, 2007; Melia et al., 2008; Siu et al., 2004). The failure can be active or latent. Active failure contributes directly to the accident while latent failure may remain dormant for some period until they lead to a catastrophic accident, through a domino effect. In the presentation, in the Swiss Cheese model, for any accident to 
$\mathrm{XJM}$

20,1

\section{6}

Figure 1.

Reason's Swiss

Cheese model

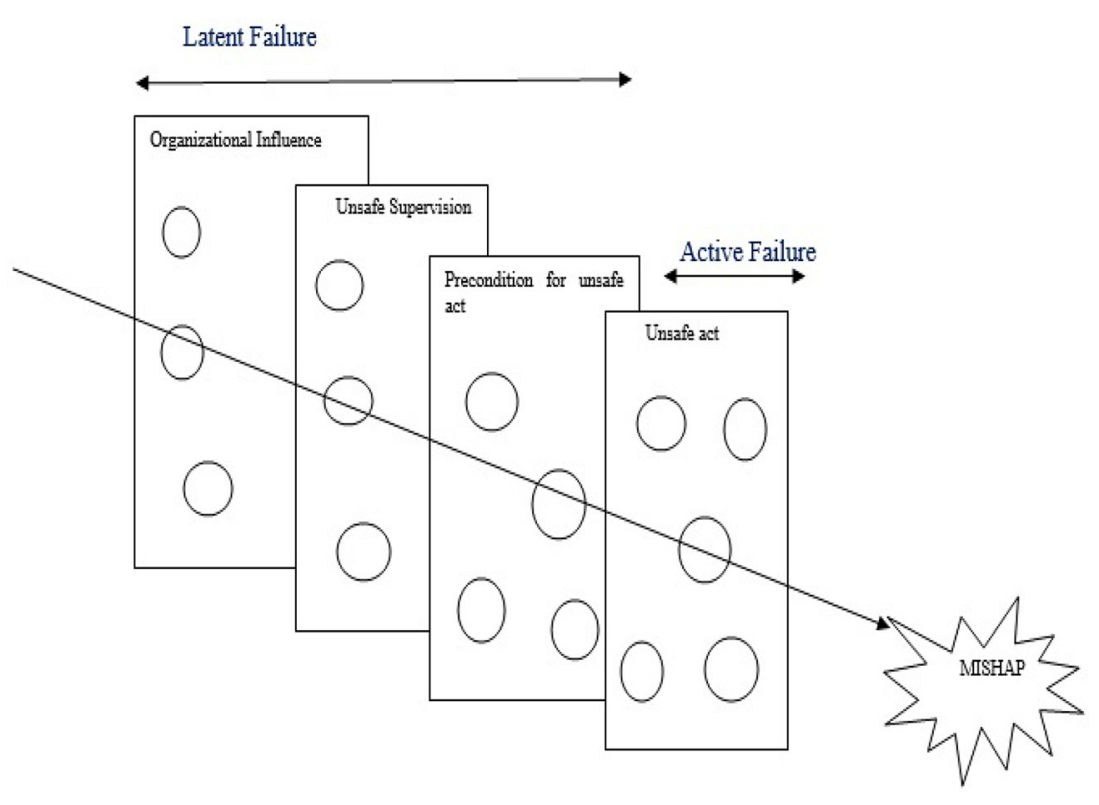

happen the holes have to be in a line. If circumstances favor and holes align then accidents occur (Gillen et al., 2002; Guo et al., 2016; Rundmo, 2000; Sawacha et al., 1999; Sklet, 2016).

\subsection{Comparison of safety models}

The Fishbone diagram is one of the root cause analysis tools to understand the cause of process failure. The Fishbone diagram categorizes the causes and is effective when used by a single person. The diagram is drawn after multiple brainstorming discussions to prioritize the relevant cause of the accident. However, in some cases, it may produce irrelevant potential causes leading to confusion and waste of time. When the problem is complex the diagram will be messy or jumbled. This method focuses on the opinion and not on evidence. It focuses on process failure rather than human error.

The failure mode effect analysis (FMEA) method is used at the core competence level. It is primarily used during the design phase to prevent the accident by considering the severity of the accident. It is a lengthy, costly and time-consuming process with no inclusion of human intervention. This analysis focus on design safety, hazard in product life cycle operational issues rather than accident causation due to human error. In this analysis items having acceptable risk is considered for ranking to find criticality of the accident.

In fault tree analysis we need an expert to identify the cause of potential failure. This method is used to generate risk factors and is beneficial for a newer system. Here also less focus is given for human error but it is an effective visual tool. It is lengthy and timeconsuming. Latent hazard is not addressed.

The Swiss Cheese model is more effective if human intervention is involved. This model triggers a human error and its forthcoming. In the Swiss Cheese model, the different levels of human error are taken into consideration, as it is a serious issue of every system. It is a structured approach which helps managers in identifying the gap that addresses potential human error. The catastrophic events are analyzed using the Swiss Cheese model to 
understand and safeguard loss of life or environmental damage or financial loss. Examples of such studies are the Space shuttle challenge and the Exxon Valdez oil spill. The space shuttle challenge incident was due to human error and poor decision-making while the Exxon Valdez oil spill incident was due to error in all levels of the organization and humans in direct contact with the system. The Swiss Cheese model can track accident causation in various levels of the organization without blaming individuals. It is the best model to address risk related to human interaction systems. "We cannot change the human condition, we can change the condition under which human works" (Reason, 2000).

\section{Cause of human electrical accidents}

\subsection{Electrical accidents}

Electricity being a widely used utility, accidents related to it are common and are a great concern, both because of their higher frequency and also their serious and even fatal outcomes. Electrical accidents mostly occur due to technical reasons or human factors or environmental causes (Goldenhar et al., 2003; Mohamed, 2002; Chen et al., 2017). Many advancements have taken place in technology to reduce accidents but Electrical accidents still are at unacceptable high levels.

Electrical safety issues can be either an incident or an accident. Electrical-related accidents are considered as an undesired events due to high electric current which results in the injury of a person or damage to property (Hoffmann and Morgeson, 1999; Roslynn, 2012; Zohar, 1980). Injury means any sort of discomfort or inconvenience to the body or any psychological injury or death that occurs due to electric current. Electrically powered equipment may pose a significant hazard to people if not maintained properly (Lingard et al., 2010; Gith et al., 2014). The major hazards due to electricity are electric shock, fire and arc flash. Electric shock is due to the body being in contact with an electric circuit or body becomes a part of an electric circuit. The severity depends on the path through the body, the magnitude of current, exposure time and type of skin (namely, wet or dry). Current can easily pass through wet skin. In addition to shock hazards, the spark from electrical equipment serves as inflammable or explosive vapor. Hazardous arc flash occurs due to high energy regardless of voltage. This happens in switches, panel board, motor control, metal clad of switchgear, transformer, motor starter, faulty equipment, etc. The explosion due to the hazardous arc creates a pressure wave which can damage a person's hearing, as well as eyesight and can cause serious burns. The live part to which an employee is exposed has to be de-energized before working on it. Working near an energized circuit can lead to accidents based on the clearance and type of device or wire.

\section{Objectives and methodology}

This study aims to develop a multi-level model to explain electrical accidents. A review of literature has been done to understand the different types of models used in the area of accident models. FMEA (Wu et al.2021) is a popular model used for the analysis of machine/ system failures and to understand the consequences of such failures and to reduce such failures. As our focus is man-related accidents where equipment failure might or might not be involved this method has not been used by us. Another popular tool for studying causes of failure or defects or even incidents is the Fishbone diagram (Varsha and Pandhare, 2015). These causes are usually grouped into those based on man, method, material and measurement. This is most suitable to depict operational causes of accidents, deeper management and other organization-related causes get missed in this tool, and hence, we have not used it here. Five whys (Serrat, 2017) is an iterative interrogative technique used to explore the cause-and-effect relationships underlying a particular problem. The primary goal of the technique is to determine the root cause of a defect or problem by repeating the 
question "Why?" Each answer forms the basis of the next question. This has been used by us in a limited way to help experts reach the "Root Causes." The Swiss Cheese model was found to be one suiting the situation of an electrical accident in electrical utility company considering the same, the following objectives were set for the work.

The objectives of this study were the following:

- To identify the different Cheese Slices and their relative positions for the model for electrical accidents.

- To identify the vulnerabilities or holes in each of the Cheese Slices.

- To arrange the Cheese Slices with holes in a Cheese model.

- To find the relative importance of each Cheese Slice (Level) and the holes (causes) in the above Cheese model for electrical accidents.

- To study the perception difference on the importance of different Cheese Slices and the holes in them in the proposed Cheese model by experts, management, supervisors and workmen.

To achieve the above objectives, the methodology with steps shown in Figure 2 was followed. A survey of literature related to electrical accidents in distribution companies was carried out to list the causes and their relationship with each other. The list of 18 causes, thus prepared was given to a group of 15 experts, 3 each from teaching and research, electrical safety consulting, electrical supply company, industrial users and railway electrification division and they were requested to recommend to remove irrelevant causes and to add causes that were missing. The experts were also requested to suggest the levels into which these causes could be aggregated. The inputs from the first round with the experts were put together and circulated to decide on levels till an agreement was obtained. After three rounds of this Delphi-like rounds of consultations with the experts, a consensus was obtained regarding the levels and the assignment of the causes to each level.

The levels and list of causes therein, thus obtained was used to frame a survey questionnaire to get the response from workers, supervisors and their managers from electrical utility providers and large industrial electricity users.

The questionnaire was distributed to 145 respondents, 114 questionnaires were filled and returned to the researcher, of which only 100 numbers were found to be usable and were, therefore, used for analysis. Inputs using the same questionnaire was also collected from 15 experts for final comparison.

\section{Results and findings}

As mentioned in the section above we have used a Delphi kind of expert survey to find the Cheese Slice (level) and the causes (holes) for electrical accidents in each Cheese Slice. The initial round of inputs from the experts yielded the following five Cheese Slices, namely, human factor issues, workplace issue, working environment and system, work culture of the organization and national standards. The initial set of 38 causes identified and given from literature were reduced to 26 in the 3 rounds of review with the experts. By the time consensus was reached, from the list of causes given, they combined 6 sets of causes, removed 7 and added 4 new ones leaving 26 causes for the study. In the consensus, they also decided to drop National Standards from the list of Cheese Slices for the model, the Cheese model slices that resulted is shown in Figure 3.

The Cheese Slices represented (Table 1) and the 26 causes or holes in the 4 Cheese Slices of the Cheese model proposed were used in the questionnaire for obtaining responses from Managers, Supervisors and workers in the survey. The respondents were asked to score 


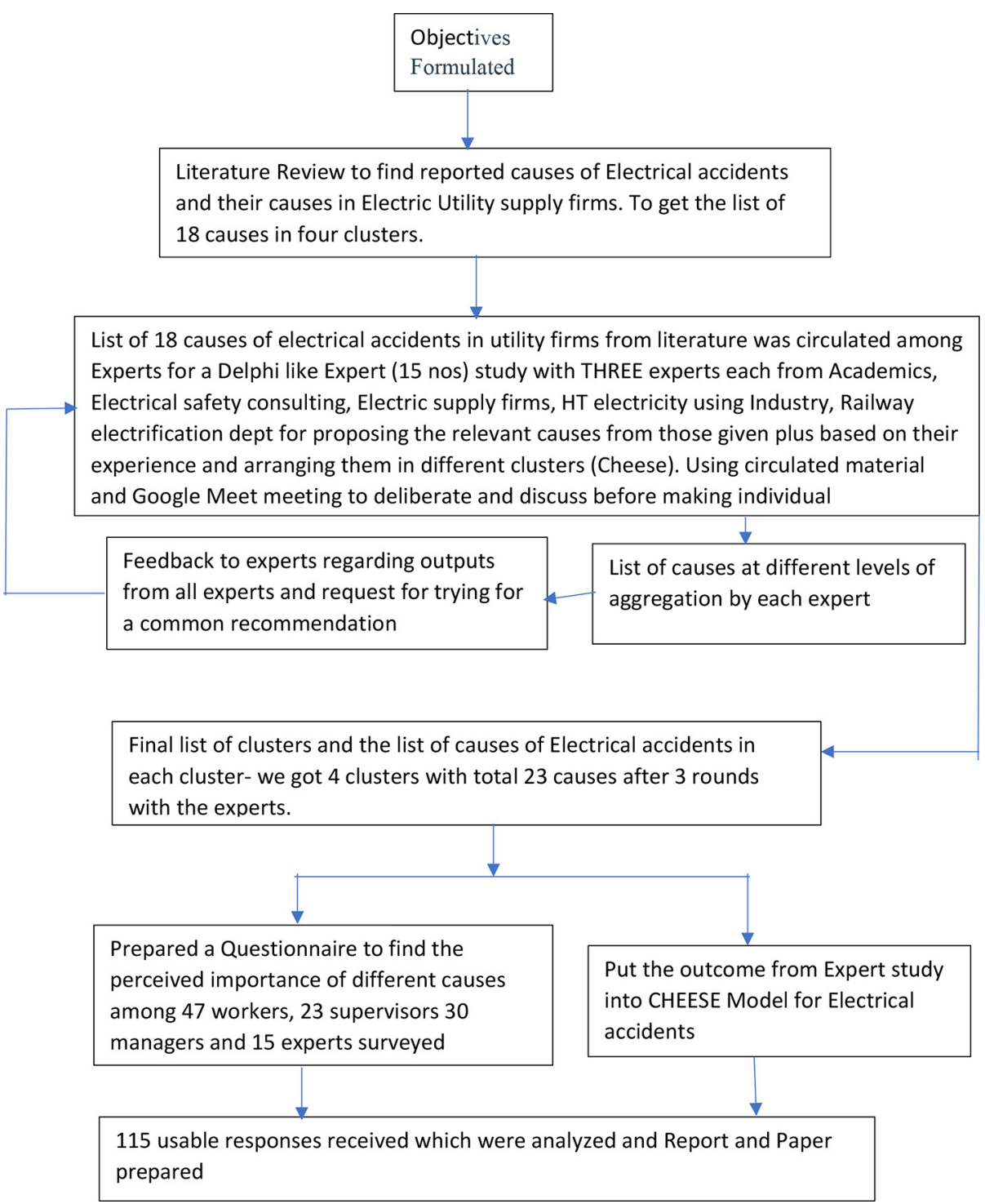

each cause on a 10-point scale with 1 for negligible importance in causing accidents and 10 for having very high importance in causing accidents based on their experience and knowledge. The experts were also given the questionnaire and the scores given by them for various causes were also taken.

The simple average score for each cause given by each group of respondents were calculated. The results from the survey are presented below. The average score given by each group for each cause is shown in Tables $2-4$, each table being devoted to one Cheese Slice-related causes from the Cheese model shown in Figure 2.

\section{Cause of human electrical accidents}

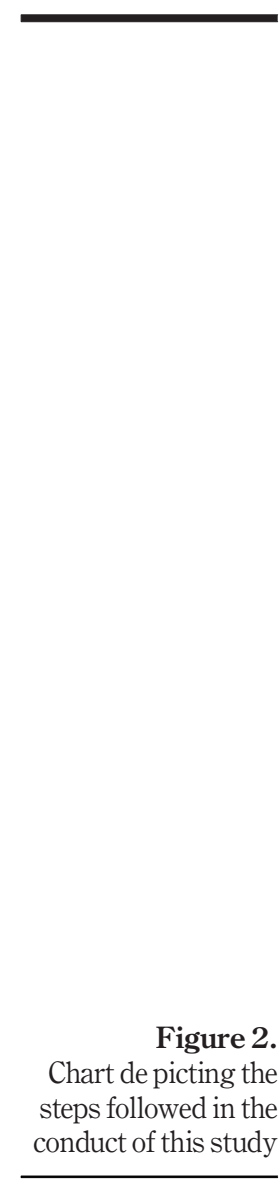




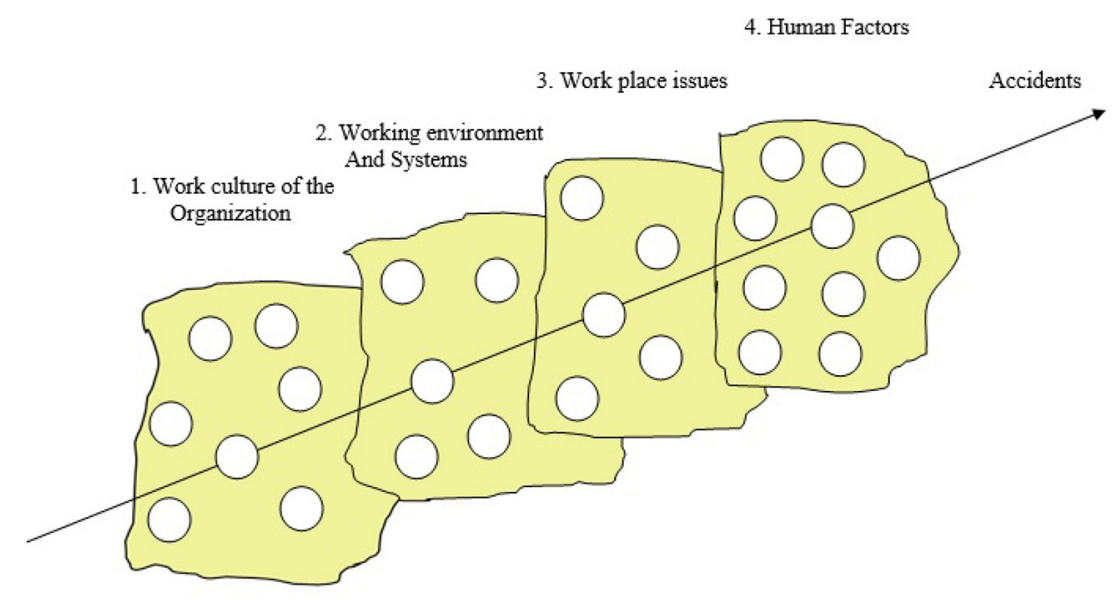

Figure 3.

The Proposed Swiss Cheese model of an electrical accident in the utility sector

\begin{tabular}{lll}
\hline Cheese Slice No. & Slice name & Holes or faults in Cheese Slice \\
\hline 1 & $\begin{array}{l}\text { Work culture of the } \\
\text { organization }\end{array}$ & $\begin{array}{l}\text { No or poor supervision, working on a live wire, lack of good } \\
\text { system knowledge, inadequate information, poor maintenance, } \\
\text { poor control of work activity, poor documentation and reporting }\end{array}$ \\
& $\begin{array}{l}\text { Working environment } \\
\text { End systems }\end{array}$ & $\begin{array}{l}\text { Electric fire or arching, flammable material, time of the day, } \\
\text { weather condition, non-isolation of system }\end{array}$ \\
Work place issues & $\begin{array}{l}\text { Unguarded live wires/less mechanical support, less clearance } \\
\text { between equipment or system, defective equipment/wear and } \\
\text { tear, improper earth procedure, back feeding }\end{array}$ \\
& Numan factors & $\begin{array}{l}\text { Not using PPE, negligence, removing wrong fuse or isolator, } \\
\text { fatigue and sleepiness, working too fast, working on the metal } \\
\text { ladder with less clearance, alcohol consumption, emotion and } \\
\text { stress, health problem or not competent }\end{array}$ \\
& &
\end{tabular}

From Table 2 above showing the importance of causes in Cheese Slice related to "Human factors" it can be seen that negligence, working on the metal ladder with less clearance, emotion and stress are the most important ones with an importance score of 9 . This is followed by the causes, not using PPE, working too fast and alcohol consumption with scores of importance ranging from 7.8 to 8.5. The other significant causes are removing the wrong fuse or isolator, fatigue and sleepiness, health problems or lack of competence with scores ranging from 7 to 7.5 .

The importance score given by managers, supervisors and that given by workmen are all in general agreement. However, the scores given by mid-level officers is on the higher side as evidenced by the column average of 8.22 against 7.99 by workmen. The importance score given by first supervisors (8.12) is lower but closer to that given by managers (8.22). The importance scores given by the panel of experts for each cause is near to or slightly higher than the highest score given by the other groups, the average score by the panel of experts being 8.49 against 8.22 by managers. It can be understood from the above that the workmen tend to give lower importance to the Human factors compared to supervisors and managers. This perception of reduced risk by them could also lead to more accidents. This observation 


\begin{tabular}{|c|c|c|c|c|c|c|c|}
\hline $\begin{array}{l}\text { Sl. } \\
\text { No. }\end{array}$ & $\begin{array}{l}\text { Holes in the Cheese Slice } \\
\text { (causes) related to } \\
\text { "Human Factors" }\end{array}$ & $\begin{array}{l}\text { Importance score by } \\
\text { Managers ( } 30 \\
\text { numbers) }\end{array}$ & $\begin{array}{l}\text { Importance } \\
\text { score by f } \\
\text { Supervisors } \\
\text { (23 numbers) }\end{array}$ & $\begin{array}{l}\text { Importance } \\
\text { score by } \\
\text { Workmen } \\
\text { (47 numbers) }\end{array}$ & $\begin{array}{l}\text { Average score of } \\
\text { importance from } \\
\text { the survey } \\
\text { (100 numbers) }\end{array}$ & $\begin{array}{l}\text { Importance score } \\
\text { by panel experts } \\
\text { (15 numbers) }\end{array}$ & $\begin{array}{l}\text { Cause of } \\
\text { human } \\
\text { electrical } \\
\text { accidents }\end{array}$ \\
\hline 1 & Not using PPE & 9 & 8.6 & 7.9 & 8.5 & 9 & \\
\hline 2 & Negligence & 9.3 & 9.1 & 8.6 & 9 & 9.4 & \\
\hline 3 & $\begin{array}{l}\text { Removing wrong Fuse or } \\
\text { isolator }\end{array}$ & 6.8 & 7 & 7.2 & 7 & 7.5 & 201 \\
\hline 4 & Fatigue and sleepiness & 7.4 & 7.6 & 7.5 & 7.5 & 8 & \\
\hline 5 & Working too fast & 8.1 & 8.2 & 8.3 & 8.2 & 8.2 & \\
\hline 6 & $\begin{array}{l}\text { Working on the metal } \\
\text { ladder with less clearance }\end{array}$ & 9.4 & 8.8 & 8.8 & 9 & 9.4 & \\
\hline 7 & Alcohol consumption & 8.2 & 7.7 & 7.5 & 7.8 & 8.5 & \\
\hline 8 & Emotion and stress & 8.8 & 9 & 9.2 & 9 & 9.1 & \\
\hline \multirow[t]{3}{*}{9} & $\begin{array}{l}\text { Health problem or not } \\
\text { competent }\end{array}$ & 7.0 & 7.1 & 6.9 & 7 & 7.3 & $\begin{array}{l}\text { Importance of causes } \\
\text { in Cheese Slice }\end{array}$ \\
\hline & Column total & 74 & 73.1 & 71.9 & 73 & 76.4 & related to "human \\
\hline & Column average & 8.22 & 8.12 & 7.99 & 8.11 & 8.49 & factors" \\
\hline
\end{tabular}

is carried through more strongly in causes such as not using PPE, negligence and consumption of alcohol which can be directly attributed to the person involved in the accident, where the workmen have given these causes a much lower importance score. This appears to be a natural tendency, as it is difficult for workmen to cast the responsibility of accidents to themselves. The importance score also indicates the general agreement among the four groups regarding the relative importance of the causes of the accidents though the panel of experts consistently gives slightly higher scores ( 0.27 on average) to each cause.

A perusal of the causes shows that most of them can be controlled or limited by tight supervision and work-related behavior correction.

From Table 3 above showing the importance of causes in the Cheese Slice of "work-related issues" it can be seen that defective equipment/wear and tear and improper earth procedure are the two most important causes of accidents with importance scores ranging from 7.9 to 8.1. The

\begin{tabular}{|c|c|c|c|c|c|c|c|}
\hline $\begin{array}{l}\text { Sl. } \\
\text { No. }\end{array}$ & $\begin{array}{l}\text { Holes in the Cheese } \\
\text { Slice (causes) related to } \\
\text { "Work-related Issues" }\end{array}$ & $\begin{array}{l}\text { Importance } \\
\text { score by } \\
\text { Managers } \\
\text { (30 numbers) }\end{array}$ & $\begin{array}{l}\text { Importance } \\
\text { score by f } \\
\text { Supervisors } \\
\text { (23 numbers) }\end{array}$ & $\begin{array}{l}\text { Importance } \\
\text { score by } \\
\text { Workmen } \\
\text { (47 numbers) }\end{array}$ & $\begin{array}{c}\text { Average score of } \\
\text { importance from the } \\
\text { survey } \\
\text { (100 numbers) }\end{array}$ & $\begin{array}{l}\text { Importance } \\
\text { score by } \\
\text { panel experts } \\
\text { (15 numbers) }\end{array}$ & \\
\hline 1 & $\begin{array}{l}\text { Unguarded live wires/ } \\
\text { less mechanical support }\end{array}$ & 6.9 & 7.1 & 7.3 & 7.1 & 7.5 & \\
\hline 2 & $\begin{array}{l}\text { Less clearance between } \\
\text { equipment or system }\end{array}$ & 7.4 & 7.6 & 7.8 & 7.6 & 7.9 & \\
\hline 3 & $\begin{array}{l}\text { Defective equipment/ } \\
\text { wear and tear }\end{array}$ & 7.7 & 8.1 & 8.4 & 8.1 & 8.6 & \\
\hline 4 & $\begin{array}{l}\text { Improper earth } \\
\text { procedure (system or } \\
\text { equipment earth) }\end{array}$ & 8.2 & 7.7 & 7.7 & 7.9 & 8.5 & $\begin{array}{r}\text { Table } 3 . \\
\text { Importance of causes }\end{array}$ \\
\hline 5 & $\begin{array}{l}\text { Back feeding } \\
\text { Column total } \\
\text { Column average }\end{array}$ & $\begin{array}{c}7.1 \\
37.3 \\
7.46\end{array}$ & $\begin{array}{c}7.2 \\
37.7 \\
7.54\end{array}$ & $\begin{array}{c}7.5 \\
38.7 \\
7.74\end{array}$ & $\begin{array}{c}7.3 \\
38 \\
7.6\end{array}$ & $\begin{array}{c}7.8 \\
40.3 \\
8.06\end{array}$ & $\begin{array}{l}\text { in Cheese Slice } \\
\text { related to "work- } \\
\text { related issues" }\end{array}$ \\
\hline
\end{tabular}


$\mathrm{XJM}$

20,1

\section{2}

Table 4.

Importance of causes in Cheese Slice related to "working environment and systems" other three causes of lower importance are unguarded live wires/less mechanical support, less clearance between equipment and back feeding with importance scores ranging from 7.9 to 8.1. The importance score given by managers, supervisors and that given by workmen are all in general agreement in this case also. However, the scores given by workmen are the highest indicated by column total of 7.74 compared with 7.54 by supervisors and 7.46 by managers. The importance scores given by the panel of experts for each cause is near to or slightly higher than the highest score given by the other groups here also. The average score given by the panel of experts is 8.06 against 7.74 by workmen which shows that the experts have on an average given importance scores of 0.3 higher than workmen (maximum in subgroup). It can be understood from the above that the workmen tend to give higher importance to work-related issues compared to the supervisors and managers. There is the perception of reduced risk by both supervisors and managers on causes related to "Work-related issues" which are more under their control. This is again indicative of the tendency of reluctance to acknowledge the seriousness of causes of accidents under their control.

A perusal of the accident causes under "Work-related issues" show that most of them could be avoided through better adoption of safety standards and its strict implementation for which managers and supervisors play a very important role.

From Table 4 above showing the importance of causes in Cheese Slice related to "Working environment and systems" it can be seen that time of the day and weather conditions are the top two important causes with importance scores of 9 and 8.7. This is followed by the non-isolation of systems in the middle with importance scores of 7.6. Electric fire or arching and flammable materials being the lower set of causes have importance scores of 6.8 and 6.5 , respectively. The importance score given by managers, supervisors and that given by workmen are all in more general agreement here also. However, the scores given by workmen and managers are the highest indicated by column total of 7.74 compared to 7.68 by supervisors. The importance scores given by the panel of experts for each cause is about 0.4 higher. It can be understood from the above that both workmen and managers tend to give similar higher scores for the causes under "Working environment systems." However, the first supervisors who are primarily responsible for controlling or mitigating these effects tend to give less slightly less importance to it and maybe that is the reason that these causes remain important.

A perusal of the causes show that most of them could be avoided through better adoption of safety standards and choice of time of work to avoid stormy weather and night or midday work during summer.

From Table 5 above showing the importance of causes in Cheese Slice related to "Work culture of the organization" it can be seen that poor documentation and reporting is the most

\begin{tabular}{|c|c|c|c|c|c|c|}
\hline $\begin{array}{l}\text { Sl. } \\
\text { No. }\end{array}$ & $\begin{array}{l}\text { Holes in the Cheese Slice } \\
\text { (causes) related to } \\
\text { "Working Environment } \\
\text { and Systems" }\end{array}$ & $\begin{array}{l}\text { Importance } \\
\text { score by } \\
\text { Managers } \\
\text { (30 nos) }\end{array}$ & $\begin{array}{l}\text { Importance } \\
\text { score by f } \\
\text { Supervisors } \\
(23 \text { nos })\end{array}$ & $\begin{array}{l}\text { Importance } \\
\text { score by } \\
\text { Workmen } \\
\text { (47 nos) }\end{array}$ & $\begin{array}{l}\text { Average score of } \\
\text { importance from } \\
\text { the survey } \\
(100 \text { nos. })\end{array}$ & $\begin{array}{l}\text { Importance } \\
\text { score by panel } \\
\text { experts } \\
\text { (15 nos.) }\end{array}$ \\
\hline 1 & Electric fire or arching & 6.8 & 6.7 & 6.9 & 6.8 & 7.1 \\
\hline 2 & Flammable material & 6.8 & 6.4 & 6.3 & 6.5 & 7 \\
\hline 3 & Time of the day & 8.7 & 9.1 & 9.2 & 9 & 9.2 \\
\hline 4 & $\begin{array}{l}\text { Weather condition (rain, } \\
\text { thunder, radiation, etc.) }\end{array}$ & 8.3 & 8.9 & 8.9 & 8.7 & 9.2 \\
\hline \multirow[t]{3}{*}{5} & Non-isolation of system & 8.1 & 7.3 & 7.4 & 7.6 & 8.3 \\
\hline & Column total & 38.7 & 38.4 & 38.7 & 38.6 & 40.8 \\
\hline & Column average & 7.74 & 7.68 & 7.74 & 7.72 & 8.16 \\
\hline
\end{tabular}




\begin{tabular}{|c|c|c|c|c|c|c|c|}
\hline $\begin{array}{l}\text { Sl. } \\
\text { No. }\end{array}$ & $\begin{array}{l}\text { Holes in the Cheese Slice } \\
\text { (causes) related to "Work } \\
\text { Culture of the organization" }\end{array}$ & $\begin{array}{l}\text { Importance } \\
\text { score by } \\
\text { Managers } \\
\text { (30 nos) }\end{array}$ & $\begin{array}{c}\text { Importance } \\
\text { score by } f \\
\text { Supervisors } \\
\text { (23 nos) }\end{array}$ & $\begin{array}{l}\text { Importance } \\
\text { score by } \\
\text { Workmen } \\
\text { (47 nos) }\end{array}$ & $\begin{array}{l}\text { Average Score of } \\
\text { Importance from } \\
\text { the survey } \\
(100 \text { nos.) }\end{array}$ & $\begin{array}{l}\text { Importance } \\
\text { score by } \\
\text { panel experts } \\
(15 \text { nos. })\end{array}$ & $\begin{array}{l}\text { Cause of } \\
\text { human } \\
\text { electrical } \\
\text { accidents }\end{array}$ \\
\hline 1 & No or poor Supervision & 8.1 & 8.1 & 8.4 & 8.2 & 8.5 & \\
\hline 2 & Working on live wire & 8.8 & 8.5 & 8.2 & 8.5 & 9.1 & \\
\hline 3 & $\begin{array}{l}\text { Lack of good system } \\
\text { knowledge and SOP }\end{array}$ & 8.6 & 7.9 & 7.5 & 8 & 8.5 & 203 \\
\hline 4 & Inadequate information & 8.1 & 8.6 & 8.8 & 8.5 & 8.9 & Table 5 \\
\hline 5 & Poor maintenance & 8.3 & 8.0 & 8.1 & 8.1 & 8.6 & Iabie 5. \\
\hline 6 & Poor control of work activity & 8.0 & 8.4 & 8.5 & 8.3 & 8.8 & $\therefore S$ \\
\hline \multirow[t]{3}{*}{7} & $\begin{array}{l}\text { Poor documentation and } \\
\text { reporting }\end{array}$ & 8.8 & 9.0 & 9.2 & 9 & 9.4 & $\begin{array}{l}\text { in Cheese Slice } \\
\text { related to "work }\end{array}$ \\
\hline & Column total & 58.7 & 58.5 & 58.7 & 58.6 & 61.8 & culture of the \\
\hline & Column average & 8.39 & 8.36 & 8.39 & 8.37 & 8.83 & organization" \\
\hline
\end{tabular}

important cause for accidents with an importance score of 9 . This is followed by the causes of working on a live wire and inadequate information at a slightly lower level of importance with a score of 8.5. The four causes, poor control of work activity, no or poor supervision, poor maintenance, lack of good system knowledge and standard operating procedure (SOP) with importance score in the range of 8.1 to 8.3 , form a set which is only marginally less important than the previous one.

In this case, the importance score given by managers, supervisors and workmen are all in greatest agreement. However, the scores given by workmen and managers are the highest indicated by column total of 8.39 compared to 8.36 by supervisors. The importance scores given by a panel of experts for each cause is about 0.5 higher, which is the highest among the four Cheese Slices. It can be understood from the above that both workmen and managers tend to give similar higher scores for the causes under "Work culture of the organization." However, the supervisors who are primarily responsible for controlling or mitigating these causes tend to give slightly less importance to it.

A perusal of the causes shows that most of them could be avoided through better documentation, training, communication and supervision to change the work culture in the organization.

A comparison among the Cheese Slice to understand the relative importance of each, using average importance score shows, that the most important slice is the one related to "Work culture of the organization" with an average importance score of 8.37, followed by Cheese Slice "Human factors" with an average score of 8.11. The Cheese Slice "Working environment and systems" with the score of 7.72 comes next closely followed by the Cheese Slice "Work-related issues" with the score of 7.6.

The column totals can be used to understand the overall role of each slice in causing accidents as they take care of the importance of causes and the number of causes in each slice. Examining the column totals we find that the Cheese Slice "Human factors" to be the highest contributor to accidents with the column total of 73 followed by the Cheese Slice "Work culture of organizations" with a column total of 58.6. The Cheese Slices "Working environment and systems" and "Workrelated issues" with similar column totals of 38.6 and 38 come at the end. The column totals were also used to understand the relative magnitude of contribution to accidents by each of the Cheese Slices. It can be seen that the Cheese Slice "Human factors" contribute to nearly double what is contributed by the Cheese Slice "Work-related issues" or "Working environment systems." The 
contribution of "Work culture of the organization" is almost 1.5 times that of Cheese Slice "Workrelated issues" or "Working environment and systems."

Examination of the causes in the slice, also indicates how issues related to the work culture of the organization such as "lack of system knowledge and SOP," "poor documentation" and "inadequate information" combined with "no or poor supervision" and highly risky practices such as "working on the live wire" lead to the working environment and system-related causes such as "electric fire," flammable material, non-isolation of systems' which again go through the holes in the Cheese related to "work-related issues" such as "unguarded live wires or less mechanical support," "less clearance between equipment or system," improper earth procedure' and "back feeding." This, combined with the holes in Cheese Slices related to "Human factors" such as "not using PPE," "negligence," "working on a metal ladder," etc. presents a line of cascading events that could easily lead to electrical accidents.

\section{Recommendations for increasing electrical safety}

In the study, the workmen gave less importance to human factors compared to managers and supervisors. Therefore, by giving necessary training and making them aware of safety issues and its impact by storytelling method, their perception can be changed to reduce risk. Necessary measures have to be taken to ensure that no one works in alcoholism or if having a health problem and emotional stress or fatigue. Care should be taken to works with proper PPE considering all safety measures without neglecting and carrying out work at the correct pace maintaining proper clearance.

To reduce work-related issues, it is necessary to ensure that system and equipment earth to be done and maintained as per standard. The defective or wear and tear equipment have to be replaced in time before any accident occurs. Care should be taken to ensure that the mechanical support for doing work is having sufficient strength and live wire is properly guarded. Steps have to be taken to ensure that there is no back feeding, the system is properly isolated before starting work on faulty devices or in cable or wire. The clearance between equipment and system specified in the standard has to be maintained without any compromise. Managers and supervisors have to consider the work-related issues with due concern and strict implementation based on safety standards has to be adopted to reduce accidents.

While working with the system, time of the day and weather or climatic conditions has to be considered. For example, the chance of an accident for a person working with an electrical system at noon during summer is more. The system, as well as the environment, will be hot and the person working with the system will be weary due to heat waves and any spark or inflammable material or non-isolation can lead to accidents which may go beyond control. Necessary cool time has to be given to the worker if the task is performed for long hours continuously.

Poor documentation and reporting system lead to poor analysis of potential hazards or accidents which leads to poor control of future accidents. Managers should ensure that each and every information has to be reported, documented properly as per standard, analyze and take remedial measures to reduce future accidents thereby maintaining the industrial standard. Managers should also ensure that the supervisor is carrying out supervision properly, no one is working in the live wire without taking safety measures and each and every worker has proper knowledge about the system. Information has to be efficiently and effectively communicated. The work-related activity has to be properly controlled and necessary maintenance has to be carried out on regular basis, as well as whenever it is required to reduce mal operation. 


\section{Conclusion and policy implications}

The main aim of the study was to use the framework of the Cheese model for studying electrical accidents in the electric utility sector. A survey of literature and multiple rounds of discussion with experts helped in reducing the causes of electrical accidents collected from literature to the ones relevant in the area of study. The survey of the three groups, managers, supervisors and workmen for their perception of the importance of each of the causes of electrical accidents provided useful insights into the working of the behavior of the system. It was found that workmen tend to under-weigh the importance of "Human factors" which are mostly related to them. The supervisors view most of the causes at slightly lower importance levels than workmen and managers, though they are in a position to control and mitigate the effects of most of these causes.

"Human factors" are seen to contribute maximum to electrical accidents followed by the "work culture of the organization." "work-related issues" and "working environment and systems" have lower contributions to causing accidents. A look at the factors under "working environment and systems" and "work-related issues" show that they closely follow from the effects of the causes in the "work culture of the organization." Therefore, we recommend a two-pronged strategy, the first part addressing the "work culture of organizations" and the second part addressing "human factors" for the effective reduction of electrical accidents. Efforts to plug the holes in the Cheese "work culture in organizations" will result in many holes in the Cheese "working environment and systems" and "workrelated issues" also getting plugged due to cascading effects of the measures taken to plug the holes in "work culture of the organization." Effective training for safe work practices, safe knowledge and closer supervision would go a long way to plug the holes in the Cheese Slice in "Human factors." The results presented in the paper clearly indicate that the above suggested actions will significantly reduce electrical accidents in the electrical utility organizations studied. Many other electrical utility organizations will be able to identify with the Cheese model for electrical accidents, the Cheese Slices and causes of accidents depicted therein, though the importance scores that they may assign each of the causes might differ slightly.

The work culture of the organization contributes more for electrical accidents compared to the working environment and systems. So first the issues related to poor supervision, working on a live wire, lack of good system knowledge, inadequate information, poor maintenance, poor control of work activity, poor documentation and reporting have to be analyzed in detail and management along with policymakers and managers have to prepare an adequate action plan and implement the same to solve this issue. Second, the issue associated with the working environment and system has to be taken care of. This includes electric fire or arching, flammable material, time of the day, weather conditions (rain, thunder, radiation, etc.) and non-isolation of the system. The true cause has to be analyzed by the safety department. The issue has to be discussed with management, managers and policymakers to take necessary action.

We believe that this framework will be useful for electrical utility companies to study and reduce electrical accidents. Policymakers can use the information for designing and developing operating standards to support industrial safety. The survey may be used for assessing and evaluating non-financial policy. Policymakers can mitigate the risk and support safety management to reduce accidents. Policy measures can be modified by focusing on the information obtained from the present study. A clear policy focusing on safety-related issues helps to benchmark guidelines for accident reduction thereby reducing social risk, enabling health and improving quality of social life. This helps in mitigating the risk of accidents in the future, building an improved safety protocol and strong safety culture. 


\section{References}

A Guide to Measuring Health and Safety Performance (2001), Hand book of HSE, December.

Burke, M.J., Chan Sarefin, S., Salvador, R., Smith, A. and Sarpy, S.A. (2008), "The role of national culture and organizational climate in safety training effectiveness", European Journal of Work and Organizational Psychology, Vol. 17 No. 1, pp. 133-152.

Casey, Griffin, M.A., Flatau Harrison, H. and Nael, A. (2017), "Safety climate and culture integrating psychological and system perspective", Journal of Occupational Health Psychology, Vol. 22 No. 3, pp. 341-351.

Census of Fatal Occupational Injuries (2014), "Bureau of Labour Statistics".

Chen, Y., Mc Cabe, B. and Hyatt, D. (2017), "Impact of individual resilience and safety climate on safety performance and psychological stress of construction workers: a case study of the Ontario construction industry", Journal of Safety Research, Vol. 61, pp. 167-176.

Chi, C.F., Yang, C.C. and Chen, Z.L. (2009), "In depth accident analysis of electrical fatalities in the construction industry", International Journal of Industrial Ergonomics, Vol. 39 No. 4, pp. 635-644.

Choudhry, R.M. (2014), "Behaviour based safety in construction sites: a case study", Accident Analysis and Prevention, Vol. 70, pp. 14-23.

Cigularov, K.P., Lancaster, P.G., Chen, P.V., Gittleman, J. and Haile, E. (2013), "Measurement equivalence of safety climate measure among hispanic and white Non-Hispanic construction workers", Safety Science, Vol. 54, pp. 58-68.

Cooper, D. (2002), "Safety culture: a model for understanding and quantifying a difficult concept", Professional Safety, Vol. 47 No. 6, pp. 30-36.

Dedobbeleer, N. and Beland, F. (1991), "A safety climate measure for construction sites", Journal of Safety Research, Vol. 22 No. 2, pp. 97-103.

Fang, D., Wu, C. and Wu, H. (2015), "Impact of supervisor on worker safety behaviour in construction projects", Journal of Management in Engineering, Vol. 31 No. 6, pp. 1-12.

Gillen, M., Baltz, D., Gassel, M., Kirsh, L. and Vaccaro, D. (2002), "Perceived safety climate, job demands and co- worker support among union and non-union injured construction workers", Journal of Safety Research, Vol. 33 No. 1, pp. 33-51.

Gludenmund, F.W. (2002), "The nature of safety culture: a review of theory and research", Safety Science, Vol. 34, pp. 215-257.

Goldenhar, L.M., William, L.J. and Swanson, N.G. (2003), "Modelling relationship between job stressor and injury and near-miss outcomes for construction labours", Work and Stress, Vol. 17 No. 3, pp. 218-240.

Guo, B., Yin, T. and Gonzalez, V. (2016), "Predicting safety behaviour in the construction industry, development and test of an integrated model", Safety Science, Vol. 84, pp. 1-11.

Hayes, B.E., Perander, J., Smecko, T. and Trask, J. (1998), "Measuring perception of work place safety: development and validation of work place safety scale", Journal of Safety Research, Vol. 29 No. 3, pp. $145-161$.

Heinrich, H.W. (1950), Industrial Accident Prevention, 3rd edition, McGraw Hill, New York.

Hoffmann, D.A. and Morgeson, F.P. (1999), "Safety related behaviour as a social exchange: the role of perceived organizational support and leader member exchange", Journal of Applied Psychology, Vol. 84 No. 2, p. 1999.

Huang, Y.H., Ho, M., Smith, G.S. and Chen, P.V. (2006), "Safety climate and self-reported injury: assessing the mediating role of employee safety control", Accident Analysis and Prevention, Vol. 38 No. 3, pp. 425-433.

Johnson, S.E. (2007), "The predictive validity of safety climate", Journal of Safety Research, Vol. 38 No. 5, pp. 511-521. 
Kapp, E.A. (2021), "The influence of superior leadership practices and perceived group safety climate on employee safety performance", Safety Science, Vol. 50 No. 4, pp. 1119-1124.

Khosravi, Y., Asilian Mahabadi, H. and Hajizadeh, E. (2014), "Factors influencing unsafe behaviour and accidents on construction sites: a review", International Journal of Occupational Safety and Ergonomics, Vol. 20 No. 1, pp. 111-125.

Lingard, H.C., Cooke, T. and Blisman, N. (2010), "Safety climate in condition of construction subcontracting: a multilevel analysis", Construction Management and Economics, Vol. 28 No. 8, pp. 813-825.

Mallik, V.B. (2014), "Determinants of agile practices: a gini index approach”, Vilakshan, XIMB Journal of Management, Vol. 11 No. 2, pp. 95-114.

Marshall, P. and Singer, M. (2018), "Heinrich's pyramid and occupational safety: a statistical validation methodology”, Safety Science, January, Vol. 101, pp. 180-189.

Melia, J.L., Mearns, K., Silva, S.A. and Lima, M.L. (2008), "Safety climate responses and the perceived risk of accidents in the construction industry", Safety Science, Vol. 46 No. 6, pp. 949-958.

Mohamed, S. (2002), "Safety climate in construction site environment", Journal of Construction Engineering and Management, Vol. 128 No. 5, pp. 375-384.

Mullai, A. and Paulson, U. (2011), "A grounded theory model for analysis of marine accidents", Accident Analysis and Prevention, Vol. 43 No. 4, pp. 1590-1603.

Mullen, J., Kellowey, E.K. and Teed, M. (2017), "Employer safety obligations, transformational leadership and their interactive effects on employee safety performance", Safety Science, Vol. 91, pp. 405-412.

Newaz, M.T., Davis, P., Jefferies, M. and Pillay, M. (2019), "Using a psychological contract of safety to predict safety climate on construction sites”, Journal of Safety Research, Vol. 68, pp. 9-19.

Reason, J. (2000), "Human error: models and management”, BMJ, 18 March, Vol. 320 No. 7237, pp. 768-770.

Roslynn, V.A. (2012), “Work Place Electrical Injury and Fatality Statistics, 2003-2010”, Electrical Safety Foundation International EFSI

Rundmo, T. (2000), "Safety climate, attitude and risk perception in norsk hydro", Safety Science, Vol. 34 Nos 1/3, pp. 47-59.

Sawacha, E., Naoum, S. and Fong, D. (1999), "Factors affecting safety performance on construction sites", International Journal of Project Management, Vol. 17 No. 5, pp. 309-315.

Serrat, O. (2017), “The five whys technique”, Knowledge Solutions, Springer, Singapore, doi: 10.1007/ 978-981-10-0983-9_32.

Siu, O., Philip, D.R. and Leung, T. (2004), "Safety climate and safety performance among construction workers in Hong Kong: the role of psychological strains as mediators", Accident Analysis and Prevention, Vol. 36 No. 3, pp. 359-366.

Sklet, S. (2016), "Safety barriers: definition, classification and performance", Journal of Loss Prevention in the Process Industries, Vol. 19 No. 5, pp. 494-506.

Thomas, S. and Bhasi, M. (2011), "A structural model for software project risk management", Vilakshan: The XIMB Journal of Management, Vol. 7 No. 3.

Tsang, Y.T., Fung, Tam, V.W. and Sing, Y. (2017), "Development of accident modelling in Hong Kong construction industry", International Journal of Construction Management, Vol. 17 No. 2, pp. 124-133.

Varsha, W. and Pandhare, S. (2015), “A review on fishbone diagram”.

Vinodkumar, M.N. and Bhasi, M. (2007), "Measuring critical factors in safety management - a survey based approach”, Vilakshan (XIMB Journal of Management), Vol. 4 No. 2, pp. 95-108.

Wu, Z., Liu, W. and Nie, W. (2021), "Literature review and prospect of the development and application of FMEA in manufacturing industry", The International Journal of Advanced Manufacturing Technology, Vol. 112 Nos 5/6, pp. 1409-1436.

Zohar, D. (1980), "Safety climate in industrial organizations: theoretical and applied implications", Journal of Applied Psychology, Vol. 65 No. 1, pp. 96-102. 


\section{Further reading}

Banuskam, L., Low Siu, S., Man, A., Hoi, S.C. and Saad, A.K. (2019), "Construction worker risk taking behaviour model with individual and organizational factors", International Journal of Environmental Research and Public Health, Vol. 16, pp. 1335-1345, doi: 10.3390/ijerph16081335.

Flin, R., Mearns, K., O' Conoor, P. and Bryden, R. (2000), "Measuring safety climate: identifying the common features", Safety Science, Vol. 34 Nos 1/3, pp. 177-192.

Heinrich, H.W., Peterson, D. and Roos, N. (1980), Incidental Accident Prevention, McGraw-Hill.

Hon, C.K.H., Hinze, J. and Chan, P.C. (2014), "Safety climate and injury occurrence of repair, maintenance, minor alteration and addition works", Facilities, Vol. 32 Nos 5/6, pp. 188-207.

HSE (1997), Safety Measurement Tool, HSE Books

Meduri, Y., S. and Rao, D. (2020), "Humanitarian efficiency and role of relief workers: testing a competency based approach", International Journal of Service Science, Management Engineering and Technology, Vol. 11 No. 4.

Zwetsloot, G., Drupsteen, L. and de Vroome, E.M.M. (2014), "Safety, reliability and worker satisfaction during organizational change", Journal of Loss Prevention in the Process Industries, Vol. 27, pp. 1-7.

\section{Corresponding author}

Beena Puthillath can be contacted at: beena.ajit1998@gmail.com

For instructions on how to order reprints of this article, please visit our website: 